\title{
Epigallocatechin gallate induces chemopreventive effects on rats with diethylnitrosamine-induced liver cancer via inhibition of cell division cycle $25 \mathrm{~A}$
}

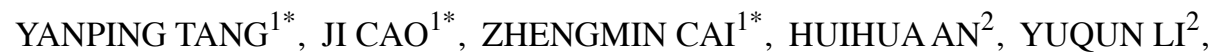 \\ YAN PENG $^{2}$, NI CHEN ${ }^{2}$, ANQIANG LUO ${ }^{2}, \mathrm{HAO} \mathrm{TAO}^{1}$ and KEZHI LI ${ }^{1}$ \\ ${ }^{1}$ Department of Research, Guangxi Medical University Cancer Hospital; ${ }^{2}$ Department of Clinical Medicine, \\ College of Basic Medicine, Guangxi Medical University, Nanning, Guangxi 530021, P.R. China
}

Received March 11, 2020; Accepted July 3, 2020

DOI: $10.3892 / \mathrm{mmr} .2020 .11463$

\begin{abstract}
Epigallocatechin gallate (EGCG), the most active monomer in green tea (GT), has demonstrated potential therapeutic and preventive effects on various tumors, including liver cancer. However, the anticancer mechanisms of EGCG in liver cancer remain to be elucidated. The abnormal expression of cell division cycle 25A (CDC25A) has been identified in liver cancer and is closely associated with malignancy and poor prognosis in patients with hepatocellular carcinoma (HCC). The present study used human hepatoma cell lines and rats with diethylnitrosamine (DEN)-induced HCC as models to investigate the association between the effect of EGCG on liver cancer and regulation of the p21waf1/Cip1/CDC25A axis. The results demonstrated that EGCG can inhibit the proliferation of HepG2 and Huh7 cells, reduce the expression of CDC25A and increase the expression of p21waf1/Cip1 in HepG2.In vivo, HCC was induced by DEN in Sprague-Dawley rats. EGCG significantly reduced tumor volume and improved the survival rates of rats with HCC. The expression levels of CDC25A mRNA and protein in liver tissues and the level of serum $\gamma$ glutamyl transpeptidase in rats treated with EGCG were significantly decreased, while p21waf1/Cip1 mRNA and protein expression levels were increased compared with the HCC group, in the process of DEN-induced HCC. No significant difference in the chemopreventive effects on liver cancer was observed between GT extract and EGCG under an EGCG equivalence condition. Thus, EGCG can suppress human hepatoma cell proliferation and prolong the survival
\end{abstract}

Correspondence to: Mr. Kezhi Li, Department of Research, Guangxi Medical University Cancer Hospital, 71 Hedi Road, Qingxiu, Nanning, Guangxi 530021, P.R. China

E-mail: scottssdssd@126.com

${ }^{*}$ Contributed equally

Key words: epigallocatechin gallate, green tea, cell division cycle 25A, p21waf1/Cip1, liver cancer of rats with $\mathrm{HCC}$, and the potential mechanism may be involved in EGCG-induced upregulation of p21waf1/Cip1 and downregulation of CDC25A.

\section{Introduction}

Liver cancer is a malignancy with a poor prognosis worldwide that seriously threatens human health (1). China has a high prevalence of liver cancer with an incidence of 466.1 per 100,000 population in 2015 (2). Liver cancer is asymptomatic in its early stages and is usually diagnosed at an advanced stage of the disease, which means successful surgery impossible. Currently, the application of chemotherapy and molecule-targeted drugs are the main approaches for the treatment of advanced liver cancer (3). However, the side effects of chemotherapy and resistance of target drugs limit the therapeutic effects for patients. Therefore, researchers have attempted to identify natural drugs with high efficiency and low toxicity for the treatment and prevention of liver cancer $(4,5)$.

Green tea (GT) is one of the most popular beverages worldwide, particularly in China (6). It has been reported that GT has beneficial effects on a number of human diseases including diabetes, cardiovascular diseases, inflammatory diseases and cancer (7-10). The main bioactive compounds in GT are catechins, which comprise a mixture of catechin, epicatechin, epigallocatechin, epicatechin gallate and epigallocatechin gallate (EGCG) (11). Of the five components, EGCG is the most abundant and bioactive catechin.

In the 1980s, our previous study investigated the chemical prevention of liver cancer in China and identified that GT can significantly inhibit hepatocarcinogenesis in rats induced by aflatoxin B1 (AFB1) and diethylnitrosamine (DEN) $(12,13)$. Subsequently, GT was provided to high-risk groups in the high-risk areas of liver cancer in the Chinese region of Guangxi and the results demonstrated that GT can reduce the incidence of liver cancer (14). EGCG exhibits versatile antitumor functions, including inhibition of proliferation, adhesion, migration, invasion and metastasis of tumor cells, as well as reduction of angiogenesis, induction of apoptosis and enhancement of anti-tumor immunity and cell cycle arrest (15-19). It has 
been reported that EGCG induces S phase arrest and inhibits cell proliferation in hepatocellular carcinoma (HCC) (20). Moreover, EGCG may act via the regulation of cell cycle regulatory proteins, including cyclin D1 and the cyclin B1/CDK1 complex, as shown in cell-based studies $(21,22)$. It has also been revealed that cell division cycle 25A (CDC25A) can activate cell $\mathrm{CDKs}$, including cyclin $\mathrm{B} 1 / \mathrm{CDK} 1$, to regulate the cell cycle (23). However, to the best of our knowledge, no previous studies have investigated the antitumor and preventive effects of EGCG on HCC via the inhibition of CDC25A. Therefore, the present study evaluated CDC25A as the target of EGCG in liver cancer. EGCG was compared with GT extract (GTE) under an EGCG equivalence condition. The present findings provided a novel mechanistic basis for EGCG application in HCC prevention and treatment.

\section{Materials and methods}

Cell culture. The human hepatoma cell lines HepG2 and Huh7 were obtained from Shanghai GeneChem Co., Ltd. The cell lines used have been authenticated using short tandem repeat profiling. The cells were maintained in DMEM (Gibco; Thermo Fisher Scientific, Inc.) supplemented with 10\% FBS (Gibco; Thermo Fisher Scientific, Inc.) and $1 \%$ penicillin/streptomycin (Beyotime Institute of Biotechnology) in a fully humidified incubator at $37^{\circ} \mathrm{C}$ with $5 \% \mathrm{CO}_{2}$.

Cell viability. HepG2 and Huh7 cells were seeded into a 96-well plate at a density of $1 \times 10^{4}$ cells per well in $100 \mu \mathrm{l}$ culture medium. The cells were incubated for $24 \mathrm{~h}$ at $37^{\circ} \mathrm{C}$, treated with various concentrations $(25,50,75,100,125$ and $150 \mu \mathrm{g} / \mathrm{ml}$ ) of EGCG (purity $>95 \%$; Sigma-Aldrich; Merck $\mathrm{KGaA}$ ) and cultured for 24,48 or $72 \mathrm{~h}$ at $37^{\circ} \mathrm{C}$ with $5 \% \mathrm{CO}_{2}$. Subsequently, $10 \mu \mathrm{l} /$ well Cell Counting Kit (CCK)-8 solution (Dojindo Molecular Technologies, Inc.) was added to each well, according to the manufacturer's instructions. The plate was incubated at $37^{\circ} \mathrm{C}$ in a $5 \% \mathrm{CO}_{2}$ atmosphere for $1 \mathrm{~h}$ and the absorbance per well was recorded at $450 \mathrm{~nm}$ on a microplate reader. The resulting data were analyzed from three independent experiments and then normalized to the absorbance of the wells containing culture medium alone. The cell viability was calculated using the following formula: Cell viability $(\%)=$ optical density $\left.(\mathrm{OD})_{\text {sample }}-\mathrm{OD}_{\text {blank }}\right) /\left(\mathrm{OD}_{\text {control }}-\mathrm{OD}_{\text {blank }}\right)$ $\mathrm{x} 100$. Inhibitory rate $(\%)=1-$ Cell viability $(\%)$. The half maximal inhibitory concentration $\left(\mathrm{IC}_{50}\right)$ values were determined using GraphPad Prism 8.0 software (GraphPad Software, Inc.).

Cell cycle assay. HepG2 cells were treated with $127.09 \mu \mathrm{g} / \mathrm{ml}$ EGCG for $48 \mathrm{~h}$ at $37^{\circ} \mathrm{C}$. Single-cell suspensions from the EGCG and control groups $\left(1 \times 10^{6}\right.$ cells/ml in ice-cold PBS; Beijing Solarbio Science \& Technology Co., Ltd.) were prepared, washed with ice-cold PBS and fixed with $70 \%$ ethanol at $4^{\circ} \mathrm{C}$ overnight. Subsequently, the cells were stained with propidium iodide (70 $\mu \mathrm{M}$; Sigma-Aldrich; Merck KGaA) solution containing RNase A $(10 \mu \mathrm{g} / \mathrm{ml}$; Fermentas; Thermo Fisher Scientific, Inc.) for $30 \mathrm{~min}$ at room temperature. The cell cycle distribution was analyzed using a FACS Calibur flow cytometer (BD Biosciences) and the percentage of each population was measured using ModFIT software (version 2.0; BD Biosciences).
Lentiviral particle generation and infection. Lentivirus with CDC25A overexpression and control lentivirus were provided by FitGene Biotechnology Co., Ltd. The CDC25A coding sequence was amplified using PrimeSTAR Max polymerase premix (Takara Biotechnology, Co., Ltd.) and verified by sequencing. The primer sequences used for the amplification of CDC25A were: Forward, 5'-CTACCGGACTCAGAT CTCGAGGCCACCATGGAACTGGGCCCGGAG-3' and reverse, 5'-GTAGTCAGATCCCATGGATCCGAGCTTCTT CAGACGACTG-3'. The following thermocycling conditions were used: Initial denaturation at $96^{\circ} \mathrm{C}$ for $4 \mathrm{~min}$; followed by 30 cycles at $96^{\circ} \mathrm{C}$ for $20 \mathrm{sec}, 60^{\circ} \mathrm{C}$ for $30 \mathrm{sec}$ and $72^{\circ} \mathrm{C}$ for $1 \mathrm{~min}$; followed by $72^{\circ} \mathrm{C}$ for $3 \mathrm{~min}$. The CDC25A coding sequence was inserted into the pLVX-Puro vector (FitGene Biotechnology Co., Ltd.), and named Lenti-CDC25A. The empty lentiviral vector (Lenti-vector) was generated as a negative control. HepG2 cells seeded in 6-well plates at a density of $1 \times 10^{5}$ cells per well were cultured in serum-free DMEM. The cells, which were $50-70 \%$ confluent, were mixed with the medium containing lentiviruses and polybrene $(10 \mu \mathrm{g} / \mathrm{ml}$; Beijing Solarbio Science \& Technology Co., Ltd.) at a multiplicity of infection of 10 . After incubation for $24 \mathrm{~h}$ at $37^{\circ} \mathrm{C}$, the supernatants were replaced by the medium containing $10 \% \mathrm{FBS}$ and cultured for a further $48 \mathrm{~h}$ at $37^{\circ} \mathrm{C}$ for subsequent experimentation. The CDC25A expression efficiency was measured using reverse transcription-quantitative (RT-q) PCR and western blotting.

Animals and their treatment. Animal experiments were ethically approved and supervised by the Ethics Committee of Ethics Committee of Guangxi Medical University Cancer Hospital (approval no. LW2018022). A total of 65 male SD rats [age, 4 weeks; weight, 100-120 g; Guangxi Medical University (Nanning, China)] were housed individually in CombiCages under controlled light (12-h light/dark cycle) and temperature $\left(22 \pm 3^{\circ} \mathrm{C}\right.$ and $40-70 \%$ relative humidity) conditions. Food and water were available ad libitum. The rats were randomly divided into six groups and the treatment methods are presented in Table I.

The animal models of HCC were induced via DEN (20 mg/ml; Sigma-Aldrich; Merck KGaA) intraperitoneally injected (100 mg/kg body weight) once a week from the 1 st-3rd week and from the 11-13th week. Moreover, $10 \mathrm{mg} / \mathrm{ml}$ EGCG (98\%; Yibeijia Teatechnology) dissolved in physiological saline and $20 \mathrm{mg} / \mathrm{ml}$ GTE (containing 49\% EGCG; Yibeijia Teatechnology) dissolved in physiological saline were prepared to be used for intragastric administration (EGCG, $25 \mathrm{mg} / \mathrm{kg}$ and GTE, $50 \mathrm{mg} / \mathrm{kg}$ body weight every day of the experiment). A curved, stainless steel 16-gauge gavage needle was used to deliver the compound to the stomach and the needle was wiped between animals. Rats that received an intraperitoneal injection of physiological saline served as the control group. Vein blood collection and liver biopsies were conducted during the 10-20th weeks. Following routine disinfection at a site below the left-sided groin of the rats, $\sim 2 \mathrm{ml}$ blood was drawn via the femoral vein puncture and serum was separated following centrifugation at $2,000 \mathrm{x}$ g for $10 \mathrm{~min}$ at room temperature. The concentrations of alanine aminotransferase (ALT; cat. no. OSR6107; Beckman Coulter, Inc.), aspartate transaminase (AST; cat. no. OSR6209; Beckman Coulter, Inc.), alkaline 
Table I. Distribution and treatment of rats.

\begin{tabular}{|c|c|c|}
\hline Group & Number & Treatment methods \\
\hline Normal & 10 & $\begin{array}{l}\text { Intraperitoneal injection of physiological saline once a week from the } 1 \text { st to } 3 \text { rd week and from } \\
\text { the } 11 \text { to } 13 \text { th week; intragastric administration of physiological saline every day }\end{array}$ \\
\hline $\mathrm{HCC}$ & 15 & $\begin{array}{l}\text { Intraperitoneal injection of DEN once a week from the } 1 \text { st to } 3 \text { rd week and from the } 11 \text { to } \\
\text { 13th week; intragastric administration of physiological saline every day }\end{array}$ \\
\hline EGCG treatment & 10 & $\begin{array}{l}\text { Intraperitoneal injection of DEN once a week from the 1st to 3rd week and from the } 11 \text { to } \\
\text { 13th week; intragastric administration of EGCG every day }\end{array}$ \\
\hline GTE treatment & 10 & $\begin{array}{l}\text { Intraperitoneal injection of DEN once a week from the 1st to 3rd week and from the } 11 \text { to } \\
\text { 13th week; intragastric administration of GTE every day }\end{array}$ \\
\hline EGCG control & 10 & $\begin{array}{l}\text { Intraperitoneal injection of physiological saline once a week from the } 1 \text { st to } 3 \text { rd week and from } \\
\text { the } 11 \text { to } 13 \text { th week; intragastric administration of EGCG every day }\end{array}$ \\
\hline GTE control & 10 & $\begin{array}{l}\text { Intraperitoneal injection of physiological saline once a week from the } 1 \text { st to } 3 \text { rd week and from } \\
\text { the } 11 \text { to } 13 \text { th week; intragastric administration of GTE every day }\end{array}$ \\
\hline
\end{tabular}

DEN dose, $100 \mu \mathrm{g} / \mathrm{kg}$ body weight; EGCG dose, $25 \mathrm{mg} / \mathrm{kg}$ body weight; GTE dose, $50 \mathrm{mg} / \mathrm{kg}$ body weight. HCC, hepatocellular carcinoma; DEN, diethylnitrosamine; EGCG, epigallocatechin gallate; GTE, green tea extract.

phosphatase (ALP; cat. no. OSR6104; Beckman Coulter, Inc.) and $\gamma$ glutamyl transpeptidase (GGT; cat. no. OSR6120; Beckman Coulter, Inc.) were determined using their respective kits on a biochemical autoanalyzer (AU5800; Beckman Coulter, Inc.).

Liver biopsies were performed as follows: Anesthesia was induced by intraperitoneal injection of sodium pentobarbital (40 mg/kg body weight). Following the preparation of the operation site by removing fur, the anesthetized rat was disinfected with iodine tincture and $75 \%$ alcohol, followed by a cut in the abdominal wall along the middle of the abdomen near the xiphoid process. The whole liver was exposed and $\sim 1.0 \times 0.6 \times 0.6 \mathrm{~cm}$ in size was excised. The incision was immediately pressed with sterile gauze for hemostasis. Subsequently, $0.2 \mathrm{ml}$ gentamicin sulfate $(40,000 \mathrm{U} / \mathrm{ml})$ was injected into the abdominal cavity of rats and the abdominal incision was sutured layer by layer. The harvested liver tissue was divided into two pieces; one was immediately frozen with liquid nitrogen $\left(-196^{\circ} \mathrm{C}\right)$, the other was fixed with $4 \%$ paraformaldehyde for $48 \mathrm{~h}$ at room temperature. Animal health and behavior were monitored daily.

When the animals exhibited a loss of appetite, lethargy and clinical symptoms of severe loss of organ function or when the maximum percentage weight loss was observed to be $>10 \%$, the animals were sacrificed. The method used was intraperitoneal injection of sodium pentobarbital $(200 \mathrm{mg} / \mathrm{kg})$. During the experiment, a total of 25 mice died. The criteria for verifying animal death were no breathing, no heartbeat and no corneal reflex. All remaining rats were sacrificed at the 30th week, the liver tissues were obtained and the tumor volume measured. For rats presenting with multiple tumors, the largest tumor was selected for statistical analysis of tumor volume. The tumor volume formula used was as follows: Volume $\left(\mathrm{mm}^{3}\right)=$ width $^{2}$ $\left(\mathrm{mm}^{2}\right) \times$ length $(\mathrm{mm}) / 2$.

$R T$ - $q P C R$. Total RNA was extracted from $2 \times 10^{5}$ cells or $50 \mathrm{mg}$ tissues using TRIzol ${ }^{\circledR}$ reagent (Invitrogen; Thermo Fisher
Scientific, Inc.) and first strand cDNA was synthesized via reverse transcription from $1 \mu \mathrm{g}$ RNA using a PrimeScript RT Reagent kit with gDNA Eraser (Takara Biotechnology Co., Ltd.), according to the manufacturer's protocol. Reverse transcription was performed for $15 \mathrm{~min}$ at $37^{\circ} \mathrm{C}$ followed by $85^{\circ} \mathrm{C}$ for $5 \mathrm{sec}$. $\mathrm{qPCR}$ was performed using a standard protocol from the SYBR ${ }^{\circledR}$ Premix Ex Taq kit (Takara Biotechnology Co., Ltd.) on the CFX96 Real-Time PCR Detection system (Bio-Rad Laboratories, Inc.), according to the manufacturer's protocol. The thermocycling conditions were: Initial denaturation at $95^{\circ} \mathrm{C}$ for $30 \mathrm{sec}$, followed by 40 cycles at $95^{\circ} \mathrm{C}$ for $5 \mathrm{sec}$ and $60^{\circ} \mathrm{C}$ for $1 \mathrm{~min}$. Primer sequences used in the present study are provided in Table II. The relative mRNA expression levels compared with the GAPDH control were analyzed with the $2^{-\Delta \Delta \mathrm{Cq}}$ method (24). The experiments were replicated three times.

Western blotting. HepG2 cells were treated with different concentrations of EGCG $(0,75,100$ and $125 \mu \mathrm{g} / \mathrm{ml})$ for $48 \mathrm{~h}$ at $37^{\circ} \mathrm{C}$. Subsequently, the cells were washed twice with ice-cold PBS. The liver tissues obtained during the 10,20 and 30th weeks of the experiment were washed 2-3 times with cold PBS followed by homogenization and incubation on ice for $30 \mathrm{~min}$. The prepared cells and tissues were lysed with RIPA lysis buffer (Sigma-Aldrich; Merck KGaA) containing 1\% phenylmethylsulfonyl fluoride (1 mM; Sigma-Aldrich; Merck KGaA) and centrifuged $\left(4^{\circ} \mathrm{C} ; 10,000 \mathrm{x} \mathrm{g} ; 10 \mathrm{~min}\right)$. The concentration of total protein was measured using the Bradford assay. Each well was loaded with $50 \mu \mathrm{g}$ protein. The samples were fractionated on a $10 \%$ SDS-PAGE, stacked at $80 \mathrm{~V}$ for $35 \mathrm{~min}$ and separated at $120 \mathrm{~V}$ for $1 \mathrm{~h}$. Following electrophoresis, the proteins were transferred to PVDF membranes (EMD Millipore). The membranes were blocked for $1 \mathrm{~h}$ at room temperature with 5\% skimmed milk and incubated overnight at $4^{\circ} \mathrm{C}$ with different primary antibodies: Anti-CDC25A rabbit polyclonal antibody (1:1,000; cat. no. GB11283; Wuhan Servicebio Technology Co., Ltd.), anti-p21waf1/Cip1 rabbit polyclonal antibody 
Table II. Primers set used for the detection of human and rat CDC25A, p21waf1/Cip1 and GAPDH.

\begin{tabular}{llr}
\hline Name & \multicolumn{1}{c}{ Sequence 5' $\rightarrow 3^{\prime}$} & Product length (base pairs) \\
\hline Human CDC25A & Forward: TTCCTCTTTTTACACCCCAGTCA & 173 \\
Human p21waf1/Cip1 & Reverse: TCGGTTGTCAAGGTTTGTAGTTC & 139 \\
Human GAPDH & Forward: TGTCCGTCAGAACCCATGC & 121 \\
Rat CDC25A & Forward: TGACTTCAACAGCGACACCCA & 138 \\
Rat p21waf1/Cip1 & Reverse: CACCCTGTTGCTGTAGCCAAA & 175 \\
Rat GAPDH & Revward: CCAAAGGAACCATTGAGAAC & 200
\end{tabular}

CDC25A, cell division cycle 25A.

(1:1,000; cat. no. GB11153; Wuhan Servicebio Technology Co., Ltd.) and anti-GAPDH mouse polyclonal antibody (1:50,000; cat. no. GB11002; Wuhan Servicebio Technology Co., Ltd.). Following the primary antibody incubation, the membranes were incubated for $1 \mathrm{~h}$ at $37^{\circ} \mathrm{C}$ with anti-rabbit or anti-mouse HRP-conjugated polyclonal secondary antibodies (1:5,000; cat. nos. A0208 and A0216; Beyotime Institute of Biotechnology). The primary antibodies and secondary antibodies were diluted in TBS-0.05\% Tween 20 (TBST)-non-fat milk. The bands were visualized by enhanced chemiluminescence detection reagents (Applygen Technologies Inc.). The PVDF membranes were scanned with a ChemiDoc MP imaging system (BioRad Laboratories, Inc.) and the densitometry was performed using Image Lab software (version 3.0; Bio-Rad Laboratories, Inc.).

Histopathological assessments. The livers of the rats were carefully removed and fixed in $4 \%$ paraformaldehyde for $48 \mathrm{~h}$ at room temperature and embedded in paraffin, then sliced into 4- $\mu \mathrm{m}$ thick sections. The sections were dewaxed in xylene, rehydrated using a descending series of ethanol, and stained with hematoxylin and eosin (H\&E) using a staining kit (Beyotime Institute of Biotechnology). Briefly, the sections were stained with $30 \mathrm{mg} / \mathrm{ml}$ hematoxylin for $15 \mathrm{~min}$ at room temperature, washed three times with water for $1 \mathrm{~min}$ for each time, and then dipped in $1 \%$ hydrochloric acid/alcohol for $10 \mathrm{sec}$. After, the sections were washed with tap water for $3 \mathrm{~min}$ and stained in $1 \%$ eosin for $1 \mathrm{~min}$ at room temperature. The sections were dehydrated in an ascending series of alcohol, transferred to xylene for $5 \mathrm{~min}$ at room temperature, and then sealed with neutral gum and covered with a glass coverslip. The sections were visualized using a light microscope (magnification, x100 or x200; Olympus Corporation).

Statistical analysis. Statistical analyses were performed using SPSS v19.0 statistical software (IBM Corp.). A one-way ANOVA followed by Dunnett's test was performed for group comparisons. An unpaired two-tailed Student's t-test was used to evaluate differences in cell cycle distribution between
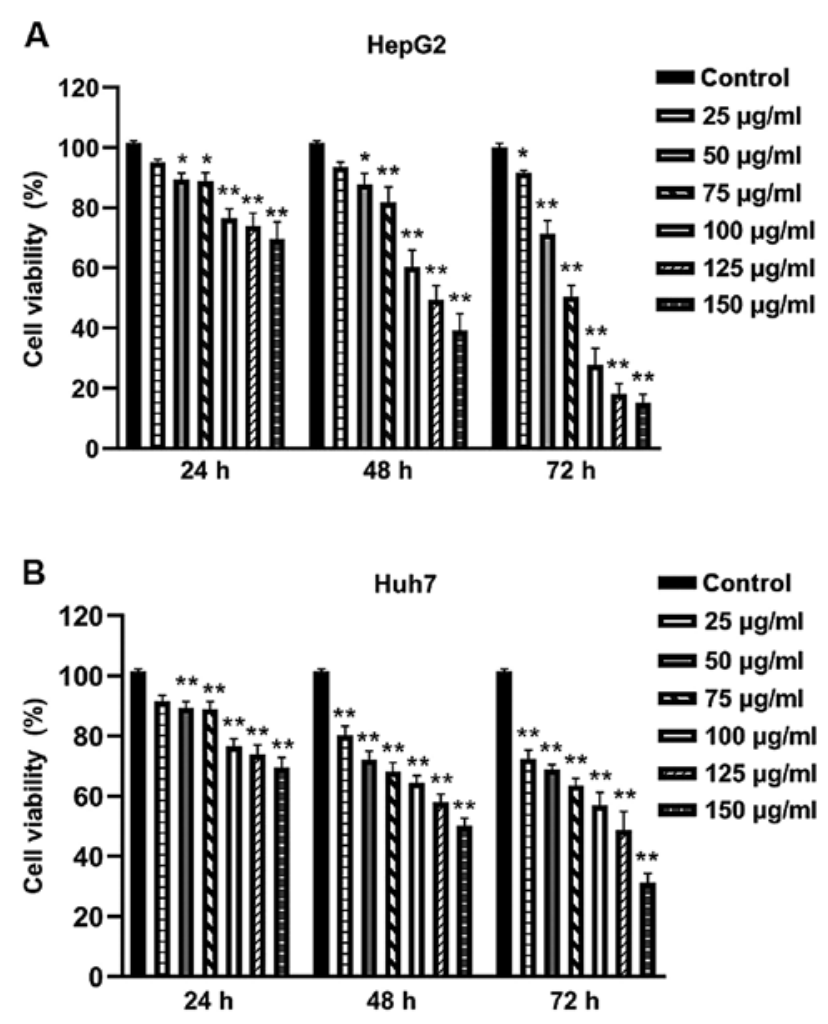

Figure 1. EGCG inhibits cell viability in HepG2 and Huh7 cells. (A) HepG2 and (B) Huh7 cells were treated with indicated concentrations of EGCG for 24, 48 and $72 \mathrm{~h}$ and cell viability were detected using a Cell Counting Kit- 8 assay. ${ }^{*} \mathrm{P}<0.05$ and ${ }^{* *} \mathrm{P}<0.01$ vs. control group. The results are representative of three independent experiments. Error bars represent mean \pm standard deviation. EGCG, epigallocatechin gallate.

EGCG group and the control group. The cell experiment was conducted independently $\geq 3$ times, and the data are presented as the mean \pm SD. The survival of the rats was estimated using the Kaplan-Meier method. A log-rank test was performed for the survival analysis after Kaplan-Meier test, and a Bonferroni test was used for correction of the obtained values from the 
A

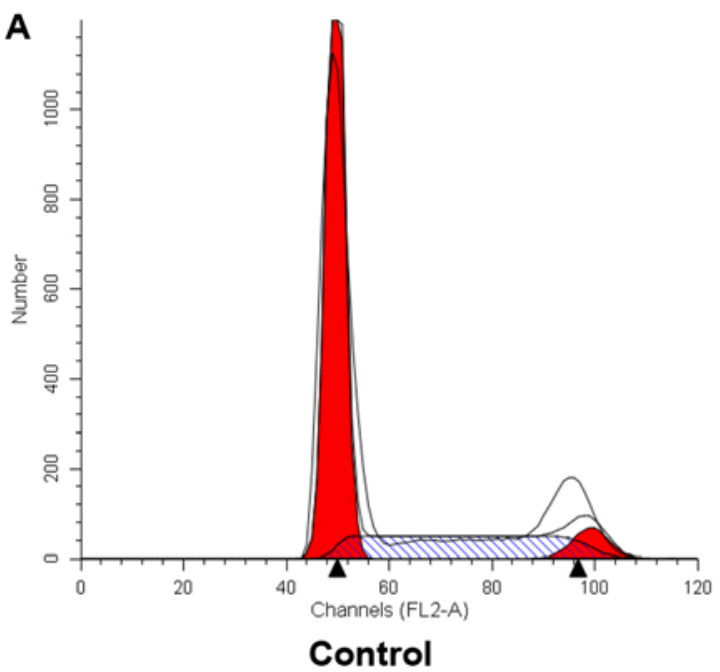

B

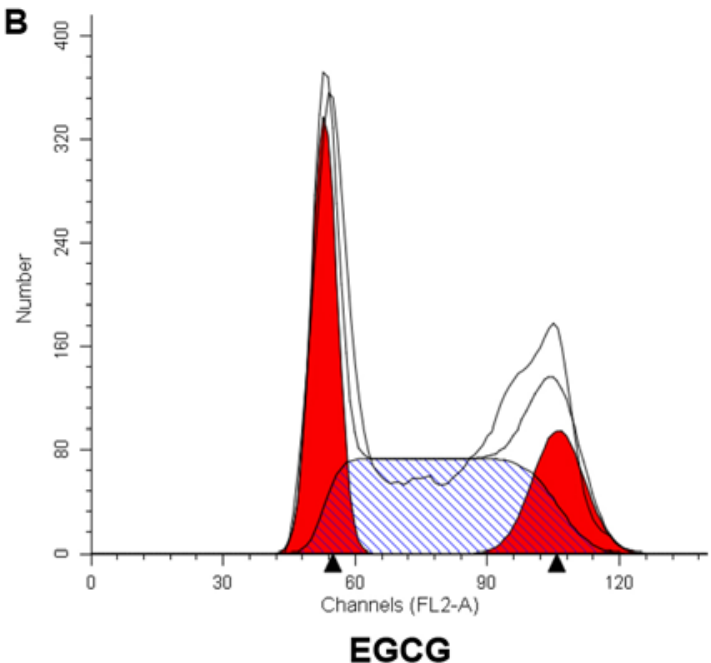

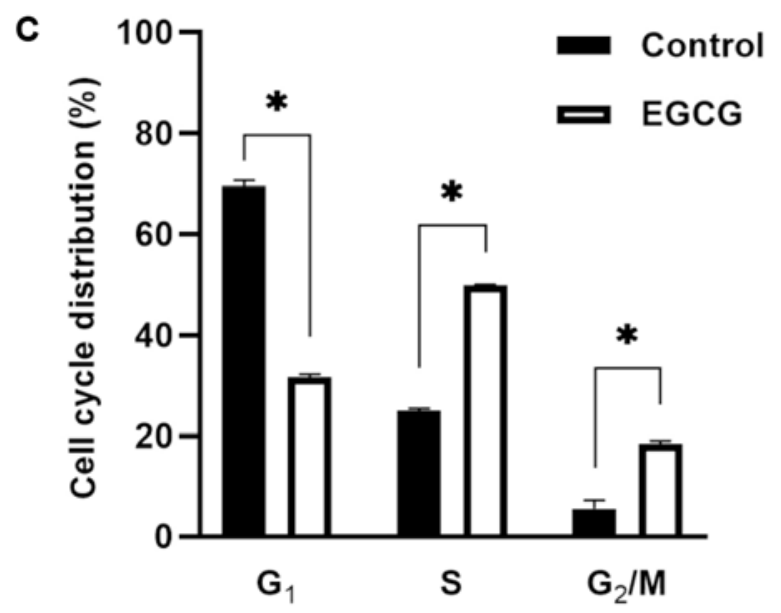

Figure 2. Effect of EGCG treatment on cell cycle in HepG2 cells. Cells from (A) control group and (B) EGCG group treated with $127.09 \mu \mathrm{g} / \mathrm{ml}$ EGCG for $48 \mathrm{~h}$, were analyzed using flow cytometry. (C) Quantitative analysis indicates the proportion of S phase and G2/M phase cells in HepG2 cells treated with EGCG for $48 \mathrm{~h}$ increased and the proportions of cells in $\mathrm{G} 1$ phase was reduced. ${ }^{*} \mathrm{P}<0.05$. EGCG, epigallocatechin gallate.

$\log$ rank tests. $\mathrm{P}<0.05$ was considered to indicate a statistically significant difference.

\section{Results}

EGCG inhibits cell viability in human hepatoma cell lines. The inhibitory effects of EGCG on HepG2 and Huh7 cells were evaluated using CCK-8 assay. Exposure of HepG2 and Huh7 cells to $25 \mu \mathrm{g} / \mathrm{ml} \mathrm{EGCG} \mathrm{led} \mathrm{to} \mathrm{a} \mathrm{notable} \mathrm{inhibition} \mathrm{of}$ cell viability, while 50, 75, 100, 125 and $150 \mu \mathrm{g} / \mathrm{ml}$ EGCG significantly enhanced this inhibitory effect (Fig. 1). In addition, a time-effect analysis indicated that $25 \mu \mathrm{g} / \mathrm{ml} \mathrm{EGCG}$ markedly decreased the viability of HepG 2 and Huh7 cells at $24 \mathrm{~h}$, which became significant at 48 and $72 \mathrm{~h}$. The decrease was significant at all time points in HepG2 and Huh7 cells treated with $50-150 \mu \mathrm{g} / \mathrm{ml}$ EGCG. These results suggested that EGCG can inhibit the proliferation of human hepatoma cell lines in a dose- and time-dependent manner.

EGCG causes cell cycle arrest in HepG2 cells. According to the cell viability (\%) presented in Fig. 1, the inhibitory rate was calculated (data not shown). The $\mathrm{IC}_{50}$ value of EGCG at $48 \mathrm{~h}$ for HepG2 cells was $127.09 \mu \mathrm{g} / \mathrm{ml}$. Thus, HepG2 cells were treated with $127.09 \mu \mathrm{g} / \mathrm{ml}$ EGCG for $48 \mathrm{~h}$. Flow cytometry was used to detect the cell cycle. The EGCG group demonstrated statistically significant differences from the control group (Fig. 2). The proportion of cells in the $S$ phase and $G_{2} / M$ phases were significantly increased compared with the control group, while the proportion of $\mathrm{G}_{1}$ phase cells was reduced significantly. Therefore, EGCG could arrest the cell cycle in the $S$ phase and $\mathrm{G}_{2} / \mathrm{M}$ phases of HepG2 cells.

EGCG induces CDC25A downregulation in HepG2 cells. The expression of CDC25A in HepG2 cells treated with 0 , 75,100 or $125 \mu \mathrm{g} / \mathrm{ml}$ EGCG for $48 \mathrm{~h}$ was examined using RT-qPCR and western blotting. In HepG2 cells treated with 100 and $125 \mu \mathrm{g} / \mathrm{ml}$ EGCG, the expression of CDC25A mRNA was significantly lower compared with untreated HepG2 cells (Fig. 3A). It was also identified that CDC25A protein expression decreased significantly in HepG2 cells following treatment with $125 \mu \mathrm{g} / \mathrm{ml}$ EGCG for $48 \mathrm{~h}$ (Fig. 3B and C).

To further demonstrate that CDC25A was the target of EGCG in inhibiting the proliferation of hepatoma cells, the effect of CDC25A overexpression on EGCG-induced 
A

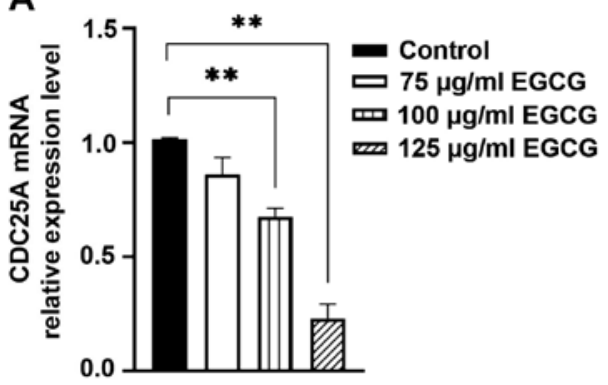

C

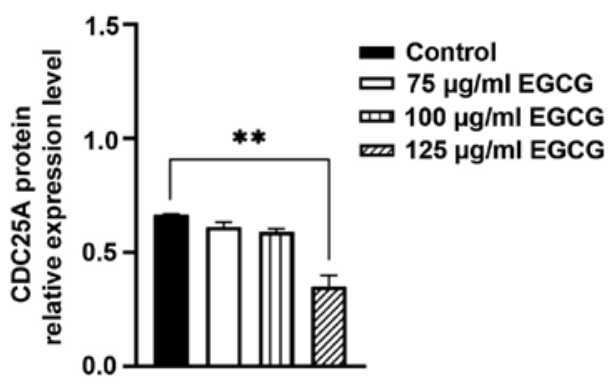

E

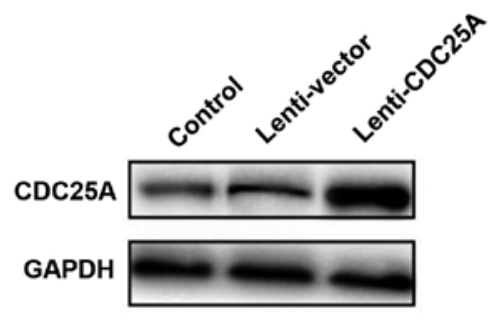

G

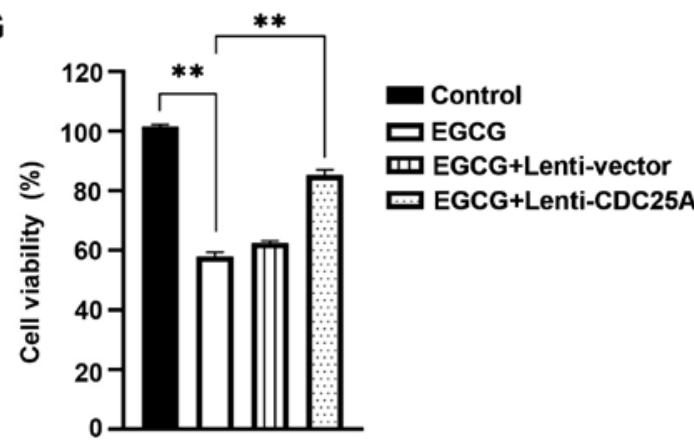

B

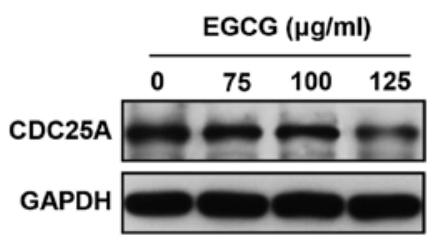

D

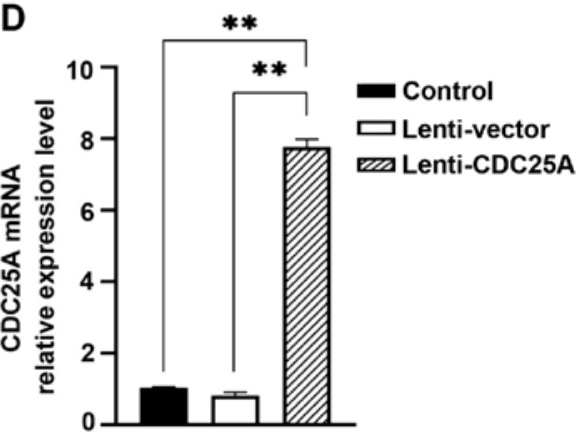

F

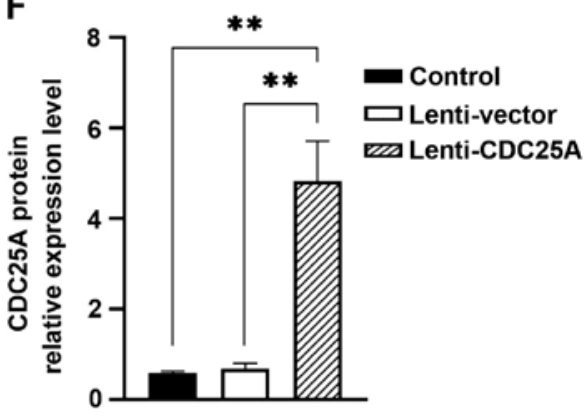

Figure 3. EGCG results in CDC25A downregulation in HepG2 cells. The cells were treated with indicated concentrations of EGCG for 48 h. (A) Total RNA was isolated from HepG2 cells and mRNA expression levels were analyzed using RT-qPCR. CDC25A expression was normalized to GAPDH. (B) Total protein lysates were collected following EGCG treatment and the expression of CDC25A protein in HepG2 cells was detected using western blotting with the indicated antibodies. (C) The relative densities of these proteins were analyzed using Image Lab software. CDC25A overexpression efficiency was confirmed via (D) RT-qPCR and (E) western blot analysis, (F) results of which were semi-quantified. (G) CDC25A overexpression reversed EGCG-induced proliferation inhibition. ${ }^{* *} \mathrm{P}<0.01$ vs. the indicated group $(\mathrm{n}=3)$. Error bars represent mean \pm standard deviation. EGCG, epigallocatechin gallate; $\mathrm{CDC} 25 \mathrm{~A}$, cell division cycle 25A; RT-qPCR, reverse transcription-quantitative PCR.

inhibition in HepG2 cells was investigated. HepG2 cells overexpressing CDC25A were constructed via transfection with Lenti-CDC25A (Fig. 3D-F). The viability changes in HepG2 cells treated with EGCG were reversed by transfection with Lenti-CDC25A, which did not occur in HepG2 cells transfected with Lenti-vector and untreated HepG2 cells (Fig. 3G).
These findings indicated that CDC25A overexpression blocked the EGCG-induced inhibition of HepG2 cell proliferation.

EGCG induces p21wafl/Cipl upregulation in HepG2 cells. As a negative transcription factor, p21waf1/Cip1 can directly regulate the transcription activity of the CDC25A 
A

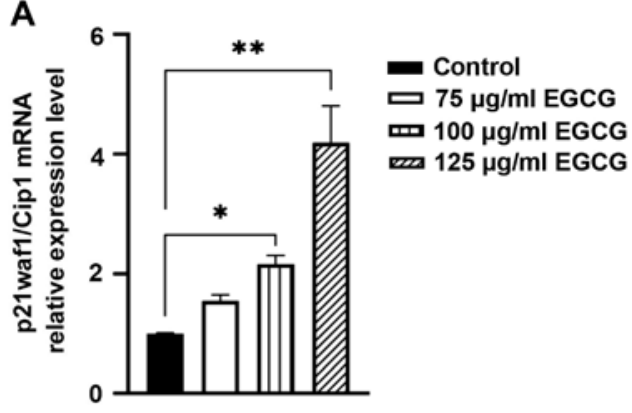

C

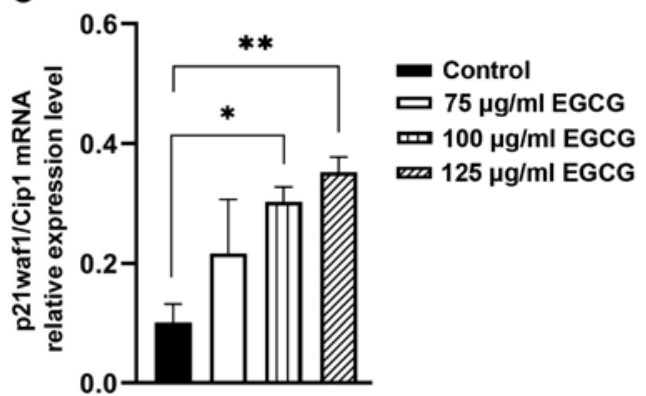

B

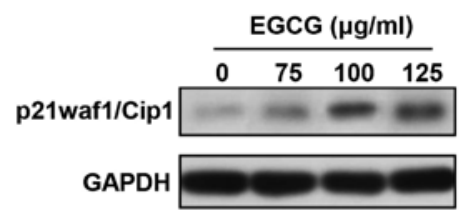

Figure 4. EGCG induces p21waf1/Cip1 upregulation in HepG2 cells. The cells were treated with indicated concentrations of EGCG for 48 h. (A) p21waf1/Cip1 mRNA levels in HepG2 cells were determined via RT-qPCR. p21waf1/Cip1 expression was normalized to GAPDH. (B) Cells were lysed and collected to detect the expression of p21waf1/Cip1 protein in HepG2 cells using western blot analysis. (C) The relative densities of these proteins were analyzed using Image Lab software. ${ }^{*} \mathrm{P}<0.05$ and ${ }^{* *} \mathrm{P}<0.01$ vs. the indicated group $(\mathrm{n}=3)$. Error bars represent mean \pm standard deviation. EGCG, epigallocatechin gallate; RT-qPCR, reverse transcription-quantitative PCR.

promoter (25). However, whether EGCG affected the expression of $\mathrm{p} 21 \mathrm{waf} 1 / \mathrm{Cip} 1$ in $\mathrm{HCC}$ required further investigation. The present study identified that the expression of p21waf1/Cip1 mRNA, which was reduced in HCC, increased with the decrease of CDC25A expression in HepG2 cells following treatment with 100 or $125 \mu \mathrm{g} / \mathrm{ml} \mathrm{EGCG}$ for $48 \mathrm{~h}$ (Fig. 4A). p21waf1/Cip1 protein expression was significantly upregulated in HepG2 cells treated with 100 and $125 \mu \mathrm{g} / \mathrm{ml}$ EGCG (Fig. 4B and C). These results suggested that EGCG can simultaneously upregulate p21waf1/Cip1 and downregulate CDC25A in vitro, which may be one of the mechanisms for EGCG-induced inhibition of hepatoma cell proliferation.

Chemopreventive effects of EGCG against HCC in vivo. Maximum percentage weight loss observed in rat from start to endpoint was $4.5 \%$. During the experiment, liver biopsies were performed for all surviving rats during the 10-20th weeks, to observe the occurrence of liver cancer in rats. During the 10th week, two rats in the HCC group were identified to have liver cirrhotic nodules. During the 20th week, two rats in the EGCG treatment group, three rats in the GTE treatment group and five rats in the HCC group developed HCC. From the 15th week onward, rat mortality in the HCC group occurred and fourteen rats died. In the EGCG treatment group, five rats died during the 24, 26, 28 and 29th weeks. From the 22nd-30th weeks, six rats in the GTE treatment group died. The succumbed rats were diagnosed with liver cancer using histopathologic analysis. At the end of the experiment, it was observed that only one rat in the HCC group, five rats in the EGCG treatment group and four rats in the GTE treatment group remained alive. The remaining animals were sacrificed following different drug treatments for 30 weeks and liver tissues were obtained.

Histopathological analysis from the living rat in the HCC group, in addition to three rats in the EGCG treatment group and three rats in the GTE treatment group that developed HCC, exhibited marked cellular infiltration, massive breakdown of hepatic tissues, plate-like and diffuse cancer cells, as well as more deeply stained nuclei and cytoplasm (Fig. 5A). A total of two rats in the EGCG treatment group and one rat in the GTE treatment group developed liver cirrhosis. The liver sections stained with H\&E revealed the formation of differently-sized liver cirrhosis pseudolobules, deformation of the hepatocyte nuclei and atypical hyperplasia of the hepatic cells (Fig. 5B). However, all rats in the control groups, including the normal, EGCG and GTE controls which were treated with EGCG or GTE only without DEN, had no liver abnormalities (Fig. 5C). Fifteen rats in the HCC group, eight rats in the EGCG treatment group and nine rats in the GTE treatment group developed HCC. The incidence of HCC in the EGCG $(80.0 \%, 8 / 10)$ and GTE groups $(90 \%, 9 / 10)$ was lower compared with the HCC group $(100 \%, 15 / 15)$, but the difference was not significant.

From the rats that died during the experiment and those sacrificed at the end of the experiment, the livers were harvested to observe the volume of the tumor (Fig. 5D). The width and length of each tumor were measured and the tumor volume was calculated. Maximum tumor diameter, volume and weight (as percentage of total body weight) was $20 \mathrm{~mm}, 1,960 \mathrm{~mm}^{3}$ and $0.77 \%$ of total body weight, respectively. It was found that, the tumor volume in the EGCG treatment group and GTE treatment group was significantly smaller compared with that in the HCC group (Fig. 5E). 

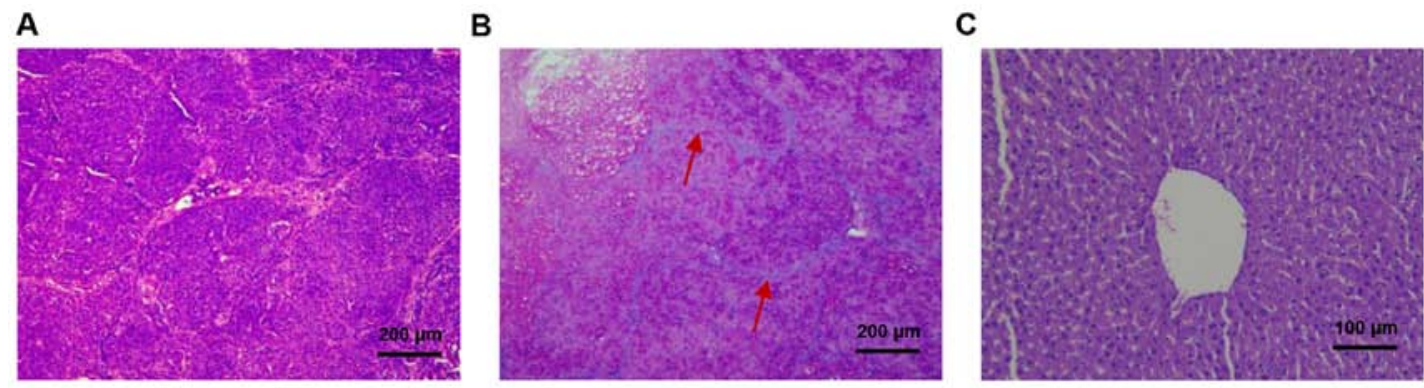

D

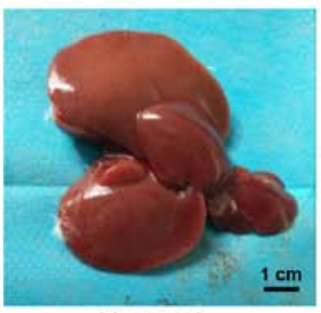

Normal

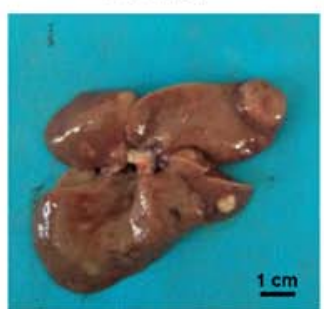

EGCG treatment

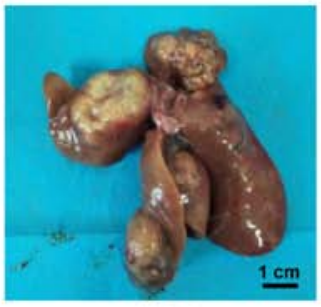

HCC

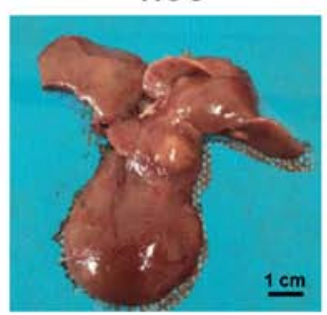

GTE treatment
E

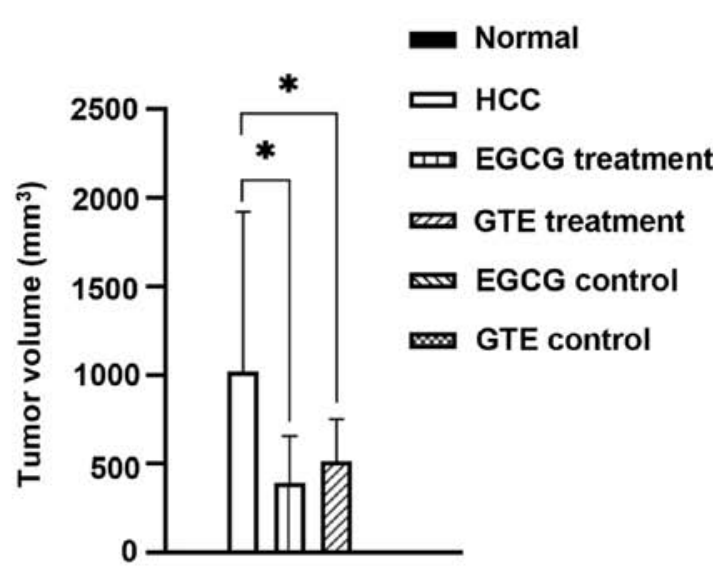

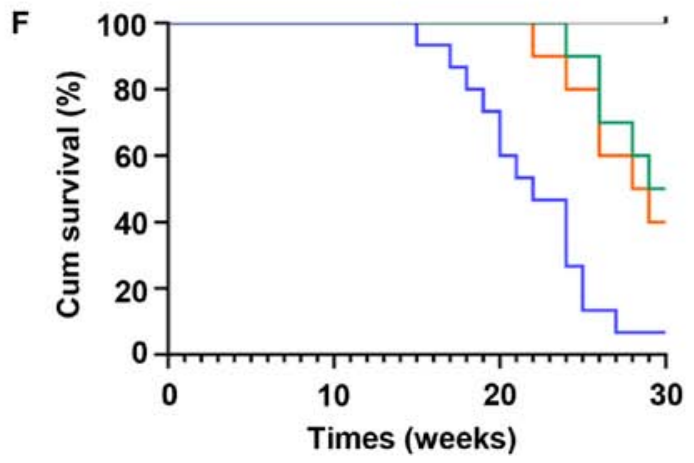

- Normal

- HCC

- EGCG treatment

- GTE treatment

- EGCG control

..... GTE control

Figure 5. EGCG induces the chemopreventive effect against HCC in vivo. The surviving rats were sacrificed and liver tissues were obtained at the end of the experiment (the 30th week). Histopathological examination of liver sections stained with hematoxylin and eosin. (A) HCC (magnification, x100), (B) liver cirrhosis (magnification, x100) and (C) healthy liver (magnification, x200). The red arrows indicate the formation of pseudo lobules in different sizes of liver cirrhosis. (D) Representative images of the livers in the normal group, HCC group, EGCG treatment group and GTE treatment group. Scale bar, 1 cm. (E) Tumor volume in all groups was calculated. All rats in control groups, including the normal, EGCG and GTE controls, had no tumor in the liver, so the tumor volume was zero. (F) Kaplan-Meier survival curves of rats. All rats in the normal, EGCG and GTE control group survived at the end of the experiment, so the survival curves overlaps. * $\mathrm{P}<0.05$ vs. the indicated group. EGCG, epigallocatechin gallate; HCC, hepatocellular carcinoma; GTE, green tea extract.

Overall survival rates were also calculated (Fig. 5F). The survival rate of rats was $6.67 \%(1 / 15)$ in the HCC group. Notably, treatment with EGCG for 30 weeks improved the rat survival to $50 \%(5 / 10)$ and treatment with GTE improved the rat survival to $40 \%(4 / 10)$. These data supported the hypothesis that EGCG and GTE significantly inhibited tumor growth and prolonged the survival rates of rats with HCC.

EGCG significantly reduces the serum GGT level in rats with DEN-induced HCC. ALT, AST, ALP and GGT are the blood indexes associated with the liver (26). During the 10-20th weeks of the experiment, the levels of ALT, AST, ALP and GGT in serum were detected. The levels of ALP, ALT and AST exhibited no significant changes, with the exception of a transient increase in ALT in the HCC group compared with the normal group during the 10th week and a transient decrease in AST in the GTE treatment group compared with the HCC group during the 20th week (Fig. 6A-C). The results demonstrated that serum GGT in HCC rats was significantly increased compared with the normal group at 10 and 20 weeks; however, the serum GGT level in rats treated 
A

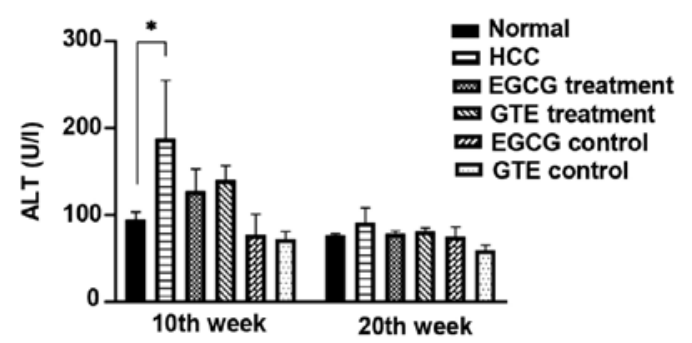

C

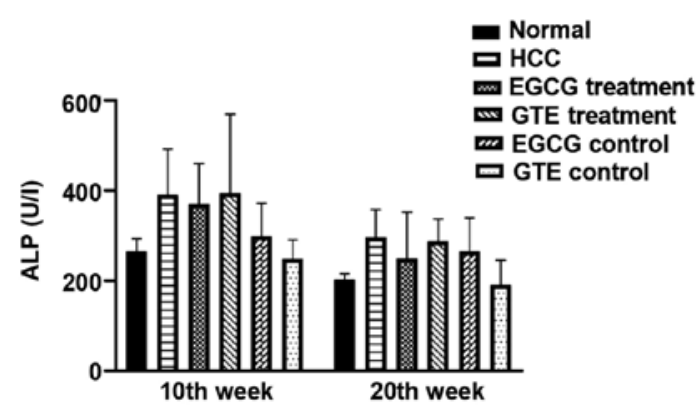

B

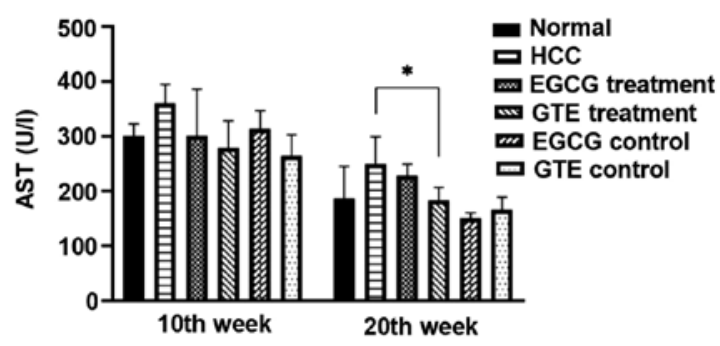

D

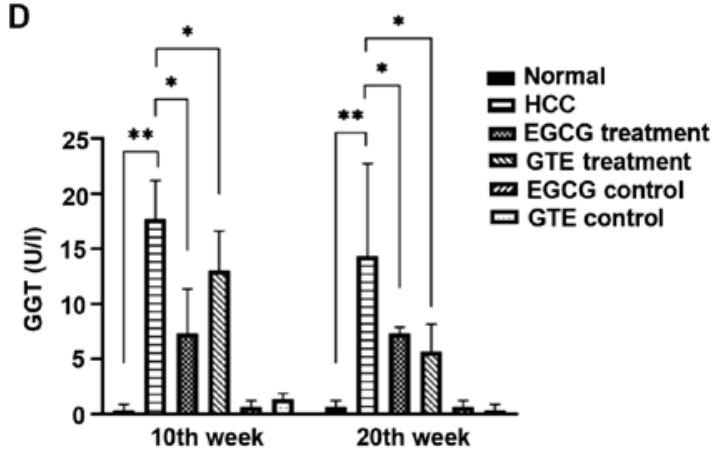

Figure 6. Treatment with EGCG and GTE resulted in significant serum GGT reduction. The vein blood collections were performed for all rats during the 10 and 20th week. The serum (A) ALT, (B) AST, (C) ALP and (D) GGT levels were detected. ${ }^{*} \mathrm{P}<0.05$ and ${ }^{* *} \mathrm{P}<0.01$ vs. the indicated group. All data are expressed as mean \pm standard deviation. EGCG, epigallocatechin gallate; GTE, green tea extract; GGT, $\gamma$ glutamyl transpeptidase; ALT, alanine aminotransferase; AST, aspartate transaminase; ALP, alkaline phosphatase.

with EGCG or GTE was significantly lower compared with the HCC group at 10 and 20 weeks (Fig. 6D). Thus, treatment with EGCG and GTE resulted in significant reductions in serum GGT.

EGCG reverses $H C C$-induced elevation of $C D C 25 A$ and reduction of p21wafl/Cipl in vivo. The dynamic changes in CDC25A and p21waf1/Cip1 were observed by detecting the expression levels of CDC25A and p21waf1/Cip1 mRNA and protein in liver tissues obtained during the 10, 20 and 30 th weeks of the experiment. During the 10th week, there was no obvious change in the expression of CDC25A mRNA (Fig. 7A) and protein (Fig. 7D and G) in the liver tissues of rats in the HCC group compared with the normal group. However, the expression levels of CDC25A mRNA and protein in the HCC group significantly increased from the 20th to the 30th week compared with the normal group. Treatment with EGCG or GTE significantly reduced the expression of CDC25A mRNA and protein in DEN-induced $\mathrm{HCC}$ rats, which began at the 20th week (Fig. 7B,C and E-G).

It was identified that the expression levels of p21waf1/Cip1 mRNA and protein in the HCC group were lower compared with those of the normal group from the 10th week to the end of the experiment. Furthermore, treatment with EGCG or GTE reversed the expression of p21waf1/Cip1 in DEN-induced HCC rats, which started at the 10th week (Fig. 7A and D). It was demonstrated that EGCG and GTE did not affect the expression levels of CDC25A and p21waf1/Cip1 in normal rats. Therefore, the data supported the hypothesis that treatment with EGCG or GTE reversed HCC-induced reduction of p21waf1/Cip1 and elevation of CDC25A, but did not affect normal rats.

\section{Discussion}

EGCG, the most active biological constituent derived from GT, has notable chemopreventive and antitumor effects (27). The aim of the present study was to simulate the process of drinking tea in daily life via oral administration of EGCG instead of intraperitoneal injection, as conducted in a previous study (28). In addition, the experiment lasted for 30 weeks and is thus of benefit to the long-term understanding of cancer prevention. The animal model selected could be used for multiple liver biopsies during the experiment, which was established early in our laboratory and continuously optimized over the course of the current study (29). In the experiments, liver tissues were collected three times for the dynamic detection of cell cycle-related molecules.

Several previous studies have reported that EGCG can exert chemopreventive effects on different carcinomas, including skin tumors (30), lung cancer (31), gastrointestinal cancer (32) and prostate cancer (33). In the present study, the tumor incidence in rats treated with EGCG demonstrated a downward trend compared with the HCC group, but no statistically significant difference was observed; a possible explanation for this is that the dose of oral EGCG used in the present study was not high enough. Oral administration of EGCG has been reported to be first absorbed in the intestines and the bioavailability is poor due to oxidation, metabolism and efflux $(34,35)$. In order to observe the effect of EGCG and GTE on the survival time of rats with HCC, the duration of this experiment was 30 weeks, while numerous previous studies were only 20 weeks (36-38); this may explain the high number of deaths. In the current study, it was identified that EGCG can reduce tumor volume and inhibit tumor growth. In addition, 
A

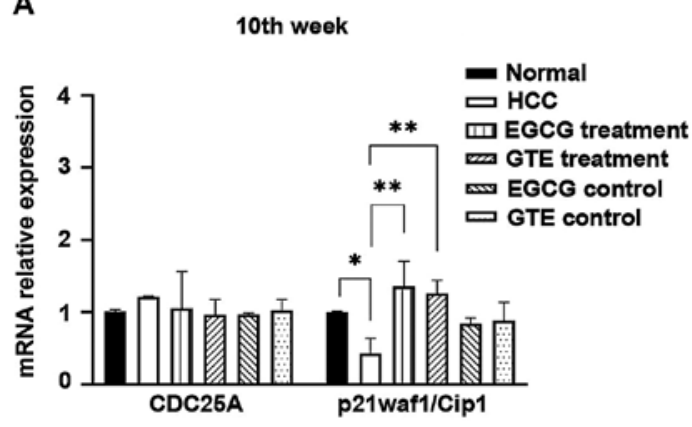

C

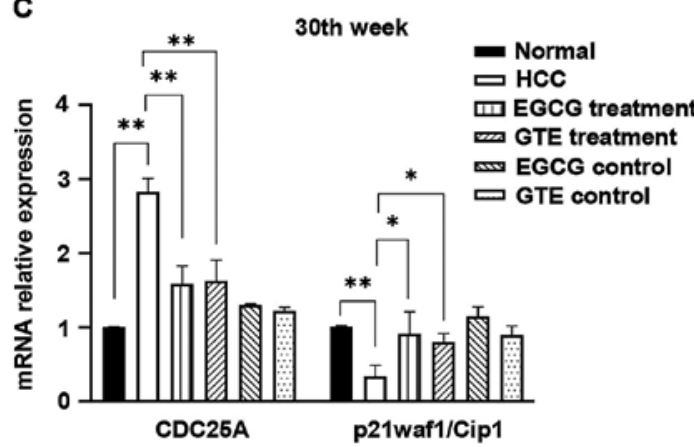

B

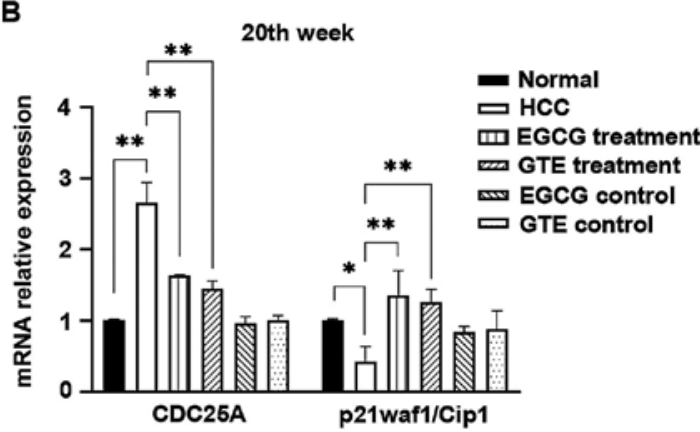

D

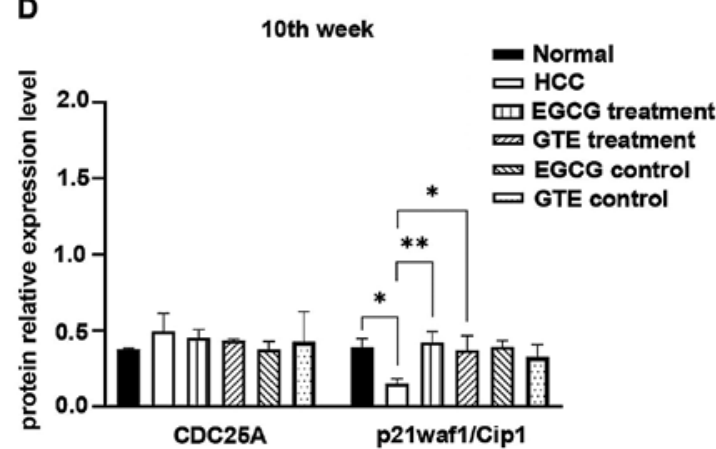

E

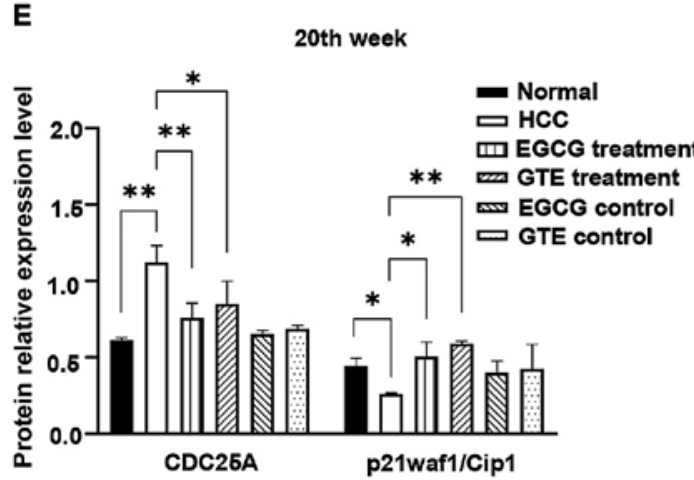

F

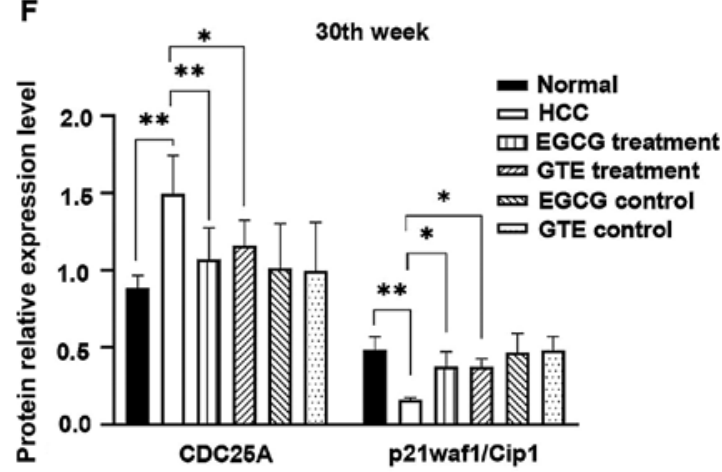

G

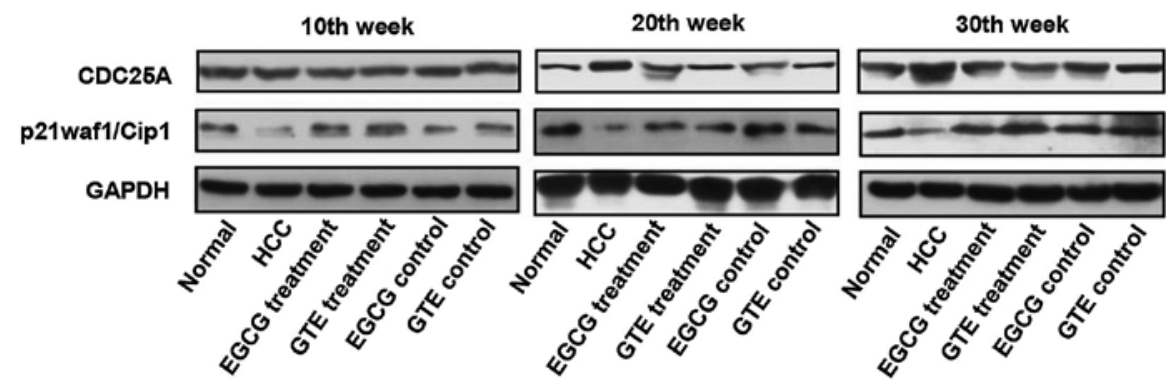

Figure 7. EGCG reverses HCC-induced elevation of CDC25A and reduction of $\mathrm{p} 21$ waf $1 / \mathrm{Cip} 1$ in vivo. Liver tissues were obtained from rats that had undergone two liver biopsies during the 10 and 20th weeks and the rats sacrificed at the end of the experiment. CDC25A and p21waf1/Cip1 mRNA expression levels in rats during the (A) 10th week, (B) 20th week and (C) 30th week were determined via RT-qPCR. CDC25A and p21waf1/Cip1 expression levels were normalized to GAPDH. The liver tissues were lysed and total protein were collected to detect the expression levels of CDC25A and p21waf1/Cip1 proteins during the (D) 10th week, (E) 20th week and (F) 30th week using western blot analysis. (G) The relative densities of these proteins were analyzed using Image Lab software. ${ }^{*} \mathrm{P}<0.05$ and ${ }^{* *} \mathrm{P}<0.01$ vs. the indicated group. Error bars represent mean \pm standard deviation. EGCG, epigallocatechin gallate; HCC, hepatocellular carcinoma; CDC25A, cell division cycle 25A; RT-qPCR, reverse transcription-quantitative PCR; GTE, green tea extract.

EGCG improved the survival of rats from $6.67 \%$ in the HCC group to $50.0 \%$ in the EGCG treatment group. The results also suggested that $25 \mathrm{mg} /$ day EGCG could prolong the survival rates of HCC rats. In vitro, EGCG exhibited dose-dependent reduction in the viability of HepG2 and Huh7 human hepatoma cells. Furthermore, EGCG could also arrest the cell cycle in the $\mathrm{S}$ phase and $\mathrm{G}_{2} / \mathrm{M}$ phases of $\mathrm{HepG} 2$ cells. Thus, $\mathrm{EGCG}$ had chemopreventive effects on HCC to a certain degree. 
It has been shown that the serum GGT levels are significantly increased in patients with HCC (39). The elevation of the GGT level in HCC may be associated with GGT gene activation by the hypomethylation status of the CCGG sites of GGT genes (40), in addition to the release of GGT from the liver cells into circulation due to DEN-induced liver damage (41). GGT is also involved in biotransformation, nucleic acid metabolism and tumorigenesis (42). Moreover, EGCG inhibits the GGT increase dose-dependently in HepG2 cells exposed to a lethal dose of ethanol (43). In the present study, treatment with EGCG reduced the elevated GGT in HCC without affecting the control group, which aided the delay of tumorigenesis.

Several mechanisms have been proposed to explain the chemopreventive effects of EGCG. The generation of reactive oxygen species (44), inhibition of multiple signaling pathways and key enzymes are hypothesized to suppress the processes of carcinogenesis (45-47). However, EGCG can influence the different molecular mechanisms, causing unique anti-cancer actions in various tumor cells (6). The present study hypothesized that the mechanism underlying the preventive effects of EGCG may be associated with the key genes involved in the pathogenesis and progression of HCC. In our previous study, identification and validation of $\mathrm{CDC} 25 \mathrm{~A}$, candidate gene screening by gene set enrichment analysis and a meta-analysis based on the cross-species comparison strategy were performed in HCC. Subsequently, high expression of CDC25A was also identified in HCC samples from AFB1-induced rat and tree shrew HCC models, in addition to human samples. Thus, CDC25A may serve an important role in the development of HCC (48).

CDC25A, a member of the CDC25 phosphatase family, can dephosphorylate and activate $\mathrm{CDK}$ s via tyrosine/threonine phosphatase activity (49). CDC25A is regarded as an important regulator of the cell cycle due to its extensive role in cell cycle transformation and mitosis (50). A number of studies have confirmed that $\mathrm{CDC} 25 \mathrm{~A}$ is an oncogene: Abnormal CDC25A can promote $G_{1} / S$ and $G_{2} / M$ transition by dephosphorylating CDK1 and CDK2 at T14/Y15, as well as CDK4 at Y17 (51-53), leading to uncontrolled cell proliferation and malignant transformation. In addition to affecting the cell cycle, CDC25A can promote high expression levels of glycolysis- related genes Glucose transporter 1, pyruvate kinase M1/2 (PKM2) and lactate dehydrogenase A via the dephosphorylation of PKM2, the key enzyme of glycolysis and participate in the metabolic regulation of tumor cells (54). Upregulation of CDC25A has frequently been identified in various tumors, and appears to be closely associated with malignancy and poor prognosis in patients with cancer (55-57).

In the process of DEN-induced HCC, the present study identified that the expression levels of CDC25A mRNA and protein in the liver tissue of rats in the HCC group were gradually increased compared with the normal group. This is consistent with the findings of our previous study, that CDC25A serves an important role in the development of HCC (48). Thus, it was suggested that treatment of HCC rats with EGCG restored CDC25A expression. In addition, the present study demonstrated that EGCG significantly reduced the expression of CDC25A in HepG2 cells. It was also found that overexpression of CDC25A could reverse EGCG-induced inhibition of HepG2 cell proliferation. Therefore, the present study provided a possible mechanism for the inhibition of liver cancer development via the repression of CDC25A in vitro and in vivo.

p21waf1/Cip1 serves an important role in controlling cell cycle progression (58). For instance, p21waf1/Cip1 contributes to the inhibition of retinoblastoma protein phosphorylation that is necessary for cell cycle progression by binding CDKs in the $G_{1}$ phase (59). p21waf1/Cip1 functions as a tumor suppressor and is usually deregulated in tumors due to the function loss of transcriptional activators, including p53 and smad3 (60). The downregulation of p21waf1/Cip1 was also observed in the present study. p21waf1/Cip1 reduces the transcriptional activity of the CDC25A promoter as a negative transcriptional repressor (25). The results of the present study demonstrated that EGCG significantly upregulated the expression of p21waf1/Cip1 between the 20-30th week, along with a decreased expression of CDC25A in vivo, which is in line with a previous study that reported that EGCG enhances the expression of p21waf1/Cip1 in colorectal cancer cells (61). However, during the 10th week of the present study, the rats treated with DEN remained in a precancerous state. Although the expression of p21waf1/Cip1 decreased significantly, it was not sufficient to affect the transcriptional activity of CDC25A; CDC25A mRNA and protein appeared to increase, but the change was not significant. Furthermore, reduced p21waf1/Cip1 was observed in HepG2 cells. However, whether the molecular mechanism of EGCG in decreasing CDC25A expression in liver cancer cells is associated with the inhibition of CDC25A promoter activity through elevated p21waf1/Cip1 remains to be investigated. It was hypothesized that treatment with EGCG caused p21waf1/Cip1 upregulation and CDC25A trans-inhibition, resulting in decreased CDC25A mRNA and protein expression levels. Thus, EGCG-induced p21waf1/Cip1 upregulation and $\mathrm{CDC} 25 \mathrm{~A}$ downregulation may led to tumor growth inhibition.

Current research concentrates on EGCG, rather than GT, in the mechanisms of prevention and treatment of tumors with GT, as the advantages of EGCG (clear chemical structure and high purity) are conducive to scientific research. In the present study, GTE and EGCG were selected as research subjects. GT has application advantages in safety, convenience, compliance and economy in daily use. There are various chemical substances in GT that possess complex biological antagonistic and synergistic properties (6). A previous study reported that GTE at an EGCG-equivalent concentration exhibits a stronger inhibition compared with EGCG alone in human squamous cell carcinoma lines (62). However, another study demonstrated that EGCG and GTE exhibit some activity as immune checkpoint inhibitors in lung cancer development (63). The results of the present study suggested that there was no significant difference in the preventive effects of GTE and EGCG on liver cancer cells under an EGCG equivalence condition. As with EGCG, treatment with GTE also improved survival via p21waf1/Cip1 upregulation and CDC25A downregulation.

To the best of our knowledge, the primary findings of the current study are the first to have shown that EGCG possesses chemopreventive properties, which can be partly explained by the reduction in CDC25A, as a key liver cancer gene reported in our previous study (48). Collectively, the 
results from the present study demonstrated that EGCG and GTE effectively reduced tumor volume, improved the survival rate of rats with HCC and inhibited hepatoma cell proliferation via the promotion of p21waf1/Cip1 and inhibition of CDC25A expression. Further efforts to identify the mechanisms underlying EGCG-induced inhibition in tumor cell viability via the $\mathrm{p} 21 \mathrm{waf} 1 / \mathrm{Cip} 1 / \mathrm{CDC} 25 \mathrm{~A}$ signal axis may facilitate the efficient treatment of liver cancer. Given its poor stability and low bioavailability, EGCG can be used in combination with other antitumor drugs and have an auxiliary or synergistic effect on HCC prevention and treatment.

\section{Acknowledgements}

The authors thank Professor Y Li and C Yang (Guangxi Medical University Cancer Hospital, Nanning, China) for crucial advice and assistance with animal experiments.

\section{Funding}

The present study was supported by the Guangxi Natural Science Foundation Program under Grant (grant no. 2017GXNSFBA198003) and The Basic Ability Enhancement Program for Young and Middle-aged Teachers of Guangxi under Grant (grant no. 2017KY0102).

\section{Availability of data and materials}

The datasets used and/or analyzed during the current study are available from the corresponding author on reasonable request.

\section{Authors' contributions}

YPT and KL designed the experiments and performed the animal experiment. JC designed the experiments and analyzed the data. ZC performed PCR and western blotting assays. HA, YL, YP, NC and AL performed the animal experiment. HT performed the histological examination. YPT wrote the manuscript. All authors read and approved the final manuscript.

\section{Ethics approval and consent to participate}

Animal experiments were conducted in accordance with the guidelines for The Care and Use of Laboratory Animals issued by the Ethics Committee of Guangxi Medical University Cancer Hospital (approval no. LW2018022).

\section{Patient consent for publication}

Not applicable.

\section{Competing interests}

The authors declare that they have no competing interests.

\section{References}

1. Yang JD, Hainaut P, Gores GJ, Amadou A, Plymoth A and Roberts LR: A global view of hepatocellular carcinoma: Trends, risk, prevention and management. Nat Rev Gastroenterol Hepatol 16: 589-604, 2019.
2. Chen W, Zheng R, Baade PD, Zhang S, Zeng H, Bray F, Jemal A Yu XQ and He J: Cancer statistics in China, 2015. CA Cancer J Clin 66: 115-132, 2016.

3. Personeni N, Pressiani T, Bozzarelli S and Rimassa L: Targeted agents for second-line treatment of advanced hepatocellular carcinoma. World J Gastrointest Oncol 11: 788-803, 2019.

4. Ilamathi M, Santhosh S and Sivaramakrishnan V: Artesunate as an anti-cancer agent targets stat-3 and favorably suppresses hepatocellular carcinoma. Curr Top Med Chem 16: 2453-2463, 2016.

5. Qian YY, Liu ZS, Yan HJ, Yuan YF, Levenson AS and Li K: Pterostilbene inhibits MTA1/HDAC1 complex leading to PTEN acetylation in hepatocellular carcinoma. Biomed Pharmacother 101: 852-859, 2018

6. Gan RY, Li HB, Sui ZQ and Corke H: Absorption, metabolism, anti-cancer effect and molecular targets of epigallocatechin gallate (EGCG): An updated review. Crit Rev Food Sci Nutr 58: 924-941, 2018.

7. Liu X, Xu W, Cai H, Gao YT, Li H, Ji BT, Shu X, Wang T, Gerszten RE, Zheng W, et al: Green tea consumption and risk of type 2 diabetes in Chinese adults: The Shanghai Women's health study and the Shanghai Men's health study. Int J Epidemiol 47: 1887-1896, 2018.

8. Quan J, Jia Z, Lv T, Zhang L, Liu L, Pan B, Zhu J, Gelb IJ, Huang $X$ and Tian J: Green tea extract catechin improves cardiac function in pediatric cardiomyopathy patients with diastolic dysfunction. J Biomed Sci 26: 32, 2019.

9. Wu D, Wang J, Pae M and Meydani SN: Green tea EGCG, T cells and T cell-mediated autoimmune diseases. Mol Aspects Med 33: 107-118, 2012.

10. Liu J, Liu S, Zhou H, Hanson T, Yang L, Chen Z and Zhou M: Association of green tea consumption with mortality from all-cause, cardiovascular disease and cancer in a Chinese cohort of 165,000 adult men. Eur J Epidemiol 31: 853-865, 2016

11. Nakagawa $\mathrm{T}$ and Yokozawa T: Direct scavenging of nitric oxide and superoxide by green tea. Food Chem Toxicol 40: 1745-1750, 2002.

12. Yan RQ, Qin GZ, Chen ZY, Li Y and Qin LL: The inhibition of green tea on the hepatocarcinogenesis induced by aflatoxin b-1 in rats. Cancer 2: 83-87, 1987 (In Chinese).

13. Li Y, Qin GZ, Qin LL, Duan XX and Yan RQ: A series of animal experiments on the prevention of liver cancer by green tea. Cancer Res Clin 4: 22-24, 1997 (In Chinese).

14. Zhang ZQ, Liu QF, Huang TR, Wu YD, Zhong SC and Yu TC: Experimental epidemiological study on the prevention of liver cancer by green tea. Guangxi Prev Med 1: 5-7, 1995 (In Chinese).

15. Shankar S, Ganapathy S, Hingorani SR and Srivastava RK: EGCG inhibits growth, invasion, angiogenesis and metastasis of pancreatic cancer. Front Biosci 13: 440-452, 2008.

16. Hazgui S, Bonnomet A, Nawrocki-Raby B, Milliot M, Terryn C, Cutrona J, Polette M, Birembaut $\mathrm{P}$ and Zahm JM: Epigallocatechin-3-gallate (EGCG) inhibits the migratory behavior of tumor bronchial epithelial cells. Respir Res 9: 33, 2008.

17. Cerezo-Guisado MI, Zur R, Lorenzo MJ, Risco A, Martín-Serrano MA, Alvarez-Barrientos A, Cuenda A and Centeno F: Implication of Akt, ERK1/2 and alternative p38MAPK signalling pathways in human colon cancer cell apoptosis induced by green tea EGCG. Food Chem Toxicol 84: 125-132, 2015.

18. Youn HS, Lee JY, Saitoh SI, Miyake K, Kang KW, Choi YJ and Hwang DH: Suppression of MyD88- and TRIF-dependent signaling pathways of Toll-like receptor by (-)-epigallocatechin-3-gallate, a polyphenol component of green tea. Biochem Pharmacol 72: 850-859, 2006.

19. Huang CH, Tsai SJ, Wang YJ, Pan MH, Kao JY and Way TD: EGCG inhibits protein synthesis, lipogenesis and cell cycle progression through activation of AMPK in p53 positive and negative human hepatoma cells. Mol Nutr Food Res 53: 1156-1165, 2009.

20. Shen X, Zhang Y, Feng Y, Zhang L, Li J, Xie YA and Luo X: Epigallocatechin-3-gallate inhibits cell growth, induces apoptosis and causes $\mathrm{S}$ phase arrest in hepatocellular carcinoma by suppressing the AKT pathway. Int J Oncol 44: 791-796, 2014.

21. Masuda M, Suzui M and Weinstein IB: Effects of epigallocatechin-3-gallate on growth, epidermal growth factor receptor signaling pathways, gene expression and chemosensitivity in human head and neck squamous cell carcinoma cell lines. Clin Cancer Res 7: 4220-4229, 2001.

22. Lim YC and Cha YY: Epigallocatechin-3-gallate induces growth inhibition and apoptosis of human anaplastic thyroid carcinoma cells through suppression of EGFR/ERK pathway and cyclin B1/CDK1 complex. J Surg Oncol 104: 776-780, 2011. 
23. Esteban V, Vázquez-Novelle MD, Calvo E, Bueno A and Sacristán MP: Human Cdc14A reverses CDK1 phosphorylation of Cdc25A on serines 115 and 320. Cell Cycle 5: 2894-2898, 2006.

24. Livak KJ and Schmittgen TD: Analysis of relative gene expression data using real-time quantitative PCR and the 2(-Delta Delta $\mathrm{C}(\mathrm{T}))$ method. Methods 25: 402-408, 2001.

25. Vigneron A, Cherier J, Barré B, Gamelin E and Coqueret $\mathrm{O}$ : The cell cycle inhibitor p21waf1 binds to the myc and cdc25A promoters upon DNA damage and induces transcriptional repression. J Biol Chem 281: 34742-34750, 2006.

26. Renner EL: Liver function tests. Baillieres Clin Gastroenterol 9: 661-677, 1995

27. Almatroodi SA, Almatroudi A, Khan AA, Alhumaydhi FA, Alsahli MA and Rahmani AH: Potential therapeutic targets of epigallocatechin gallate (EGCG), the most abundant catechin in green tea, and its role in the therapy of various types of cancer. Molecules 25: 3146, 2020.

28. Darweish MM, Abbas A, Ebrahim MA and Al-Gayyar MM: Chemopreventive and hepatoprotective effects of Epigallocatechin-gallate against hepatocellular carcinoma: Role of heparan sulfate proteoglycans pathway. J Pharm Pharmacol 66 1032-1045, 2014

29. Liang HJ, Wei W, Kang XN, Guo K, Cao J, Su JJ, Yang C, Ou C, Li Y and Liu YK: Differentially expressed proteins in the precancerous stage of rat hepatocarcinogenesis induced by diethylnitrosamine. Zhonghua Gan Zang Bing Za Zhi 17: 669-674 2009 (In Chinese)

30. Yoshizawa S, Horiuchi T, Fujiki H, Yoshida T, Okuda T and Sugimura T: Antitumor promoting activity of (-)-epigallocatechin gallate, the main constituent of 'Tannin' in green tea. Phytother Res 1: 44-47, 1987.

31. Wang ZY, Hong JY, Huang MT, Reuhl KR, Conney AH and Yang CS: Inhibition of N-nitrosodiethylamine- and 4-(methyln itrosamino)-1-(3-pyridyl)-1-butanone-induced tumorigenesis in A/J mice by green tea and black tea. Cancer Res 52:1943-1947, 1992.

32. XuQ, Yang CH,LiuQ,JinXF,XuXT,TongJL,XiaoSDandRanZH: Chemopreventive effect of epigallocatechin-3-gallate (EGCG) and folic acid on the N-methyl-N'-nitro-N-nitrosoguanidine (MNNG)-induced gastrointestinal cancer in rat model. J Dig Dis 12: 181-187, 2011.

33. Gupta S, Hastak K, Ahmad N, Lewin JS and Mukhtar H: Inhibition of prostate carcinogenesis in TRAMP mice by oral infusion of green tea polyphenols. Proc Natl Acad Sci USA 98 10350-10355, 2001.

34. Chen L, Lee MJ, Li H and Yang CS: Absorption, distribution, elimination of tea polyphenols in rats. Drug Metab Dispos 25: 1045-1050, 1997.

35. Kale A, Gawande S, Kotwal S, Netke S, Roomi W, Ivanov V, Niedzwiecki A and Rath M: Studies on the effects of oral administration of nutrient mixture, quercetin and red onions on the bioavailability of epigallocatechin gallate from green tea extract. Phytother Res 24 (Suppl 1): S48-S55, 2010.

36. Ding YF, Wu ZH, Wei YJ, Shu and Peng YR: Hepatic inflammation-fibrosis-cancer axis in the rat hepatocellular carcinoma induced by diethylnitrosamine. J Cancer Res Clin Oncol 143: 821-834, 2017.

37. Cha JH, Bae SH, Kim HL, Park NR, Choi ES, Jung ES, Choi JY and Yoon SK: Branched-chain amino acids ameliorate fibrosis and suppress tumor growth in a rat model of hepatocellular carcinoma with liver cirrhosis. PLoS One 8: e77899, 2013.

38. Xu M, Zhao Q, Shao D, Liu H, Qi J and Qin C: Chenodeoxycholic acid derivative HS-1200 inhibits hepatocarcinogenesis and improves liver function in diethylnitrosamine-exposed rats by downregulating MTH1. Biomed Res Int 2017: 1465912, 2017.

39. Xu XS, Wan Y, Song SD, Chen W, Miao RC, Zhou YY, Zhang LQ, Qu K, Liu SN, Zhang YL, et al: Model based on $\gamma$-glutamyltransferase and alkaline phosphatase for hepatocellular carcinoma prognosis. World J Gastroenterol 20 : 10944-10952, 2014.

40. Yao D, Jiang D, Huang Z, Lu J, Tao Q, Yu Z and Meng X: Abnormal expression of hepatoma specific gamma-glutamyl transferase and alteration of gamma-glutamyl transferase gene methylation status in patients with hepatocellular carcinoma. Cancer 88: 761-769, 2000.

41. Shaarawy SM, Tohamy AA, Elgendy SM, Elmageed ZY, Bahnasy A, Mohamed MS, Kandil E and Matrougui K: Protective effects of garlic and silymarin on NDEA-induced rats hepatotoxicity. Int J Biol Sci 5: 549-557, 2009.
42. Ma H, Zhang L, Tang B, Wang Y, Chen R, Zhang B, Chen Y, Ge N, Wang Y, Gan Y, et al: $\gamma$-Glutamyltranspeptidase is a prognostic marker of survival and recurrence in radiofrequency-ablation treatment of hepatocellular carcinoma. Ann Surg Oncol 21: 3084-3089, 2014.

43. Lee SI, Kim HJ and Boo YC: Effect of green tea and (-)-epigallocatechin gallate on ethanol-induced toxicity in HepG2 cells. Phytother Res 22: 669-674, 2008.

44. Yang GY, Liao J, Kim K, Yurkow EJ and Yang CS: Inhibition of growth and induction of apoptosis in human cancer cell lines by tea polyphenols. Carcinogenesis 19: 611-616, 1998

45. Liang YC, Lin-shiau SY, Chen CF and Lin JK: Suppression of extracellular signals and cell proliferation through EGF receptor binding by (-)-epigallocatechin gallate in human A431 epidermoid carcinoma cells. J Cell Biochem 67: 55-65, 1997.

46. Gupta S, Hastak K, Afaq F, Ahmad N and Mukhtar H: Essential role of caspases in epigallocatechin-3-gallate-mediated inhibition of nuclear factor kappa B and induction of apoptosis. Oncogene 23: 2507-2522, 2004.

47. Berger SJ, Gupta S, Belfi CA, Gosky DM and Mukhtar H: Green tea constituent (--)-epigallocatechin-3-gallate inhibits topoisomerase I activity in human colon carcinoma cells. Biochem Biophys Res Commun 288: 101-105, 2001.

48. Lu X, Sun W, Tang Y, Zhu L, Li Y, Ou C, Yang C, Su J, Luo C, $\mathrm{Hu} \mathrm{Y}$ and Cao J: Identification of key genes in hepatocellular carcinoma and validation of the candidate gene, cdc25a, using gene set enrichment analysis, meta-analysis and cross-species comparison. Mol Med Rep 13: 1172-1178, 2016.

49. Terada Y, Tatsuka M, Jinno S and Okayama H: Requirement for tyrosine phosphorylation of Cdk4 in G1 arrest induced by ultraviolet irradiation. Nature 376: 358-362, 1995.

50. Shen T and Huang S: The role of Cdc25A in the regulation of cell proliferation and apoptosis. Anticancer Agents Med Chem 12: 631-639, 2012.

51. Bartek J and Lukas J: Mammalian G1- and S-phase checkpoints in response to DNA damage. Curr Opin Cell Biol 13: 738-747, 2001.

52. Lindqvist A, Rodríguez-Bravo V and Medema RH: The decision to enter mitosis: Feedback and redundancy in the mitotic entry network. J Cell Biol 185: 193-202, 2009.

53. Lavarone A and Massagué J: Repression of the CDK activator Cdc25A and cell-cycle arrest by cytokine TGF-beta in cells lacking the CDK inhibitor p15. Nature 387: 417-422, 1997.

54. Liang J, Cao R, Zhang Y, Xia Y, Zheng Y, Li X, Wang L, Yang W and Lu Z: PKM2 dephosphorylation by Cdc25A promotes the Warburg effect and tumorigenesis. Nat Commun 7: 12431, 2016.

55. Yamashita Y, Kasugai I, Sato M, Tanuma N, Sato I, Nomura M, Yamashita K, Sonoda Y, Kumabe T, Tominaga T, et al: CDC25A mRNA levels significantly correlate with $\mathrm{Ki}-67$ expression in human glioma samples. J Neurooncol 100: 43-49, 2010.

56. Singh L, Pushker N, Sen S, Singh MK, Bakhshi S, Chawla B and Kashyap S: Expression of CDC25A and CDC25B phosphatase proteins in human retinoblastoma and its correlation with clinicopathological parameters. Br J Ophthalmol 99: 457-463, 2015.

57. Brunetto E, Ferrara AM, Rampoldi F, Talarico A, Cin ED, Grassini G, Spagnuolo L, Sassi I, Ferro A, Cuorvo LV, et al: CDC25A protein stability represents a previously unrecognized target of HER2 signaling in human breast cancer: Implication for a potential clinical relevance in trastuzumab treatment. Neoplasia 15: 579-590, 2013.

58. Weiss RH: p21Waf1/Cip1 as a therapeutic target in breast and other cancers. Cancer Cell 4: 425-429, 2003.

59. Harper JW, Adami GR, Wei N, Keyomarsi K and Elledge SJ: The p21 Cdk-interacting protein Cip1 is a potent inhibitor of G1 cyclin-dependent kinases. Cell 75: 805-816, 1993.

60. Abbas T and Dutta A: p21 in cancer: Intricate networks and multiple activities. Nat Rev Cancer 9: 400-414, 2009.

61. Zhang X, Min KW, Wimalasena J and Baek SJ: Cyclin D1 degradation and $\mathrm{p} 21$ induction contribute to growth inhibition of colorectal cancer cells induced by epigallocatechin-3-gallate. J Cancer Res Clin Oncol 138: 2051-2060, 2012.

62. Liu X, Zhang DY, Zhang W, Zhao X, Yuan C and Ye F: The effect of green tea extract and EGCG on the signaling network in squamous cell carcinoma. Nutr Cancer 63: 466-475, 2011.

63. Rawangkan A, Wongsirisin P, Namiki K, Iida K, Kobayashi Y, Shimizu Y, Fujiki $\mathrm{H}$ and Suganuma M: Green tea catechin is an alternative immune checkpoint inhibitor that inhibits PD-L1 expression and lung tumor growth. Molecules 23: 2071, 2018.

This work is licensed under a Creative Commons Attribution-NonCommercial-NoDerivatives 4.0 International (CC BY-NC-ND 4.0) License. 